\title{
Os desafios de formar-se professor formador e autor na Educação a Distância
}

\section{The challenges of becoming author and professor in Distance Education}

\author{
Maria Teresa Menezes Freitas ${ }^{1}$ \\ Aléxia Pádua Franco ${ }^{2}$
}

\begin{abstract}
RESUMO
Este artigo tem por objetivo problematizar e discutir os desafios de formar professores autores e formadores para atuar em cursos na modalidade a distância, a partir de experiências e reflexões acumuladas pelas autoras em atividades de docência e gestão no Centro de Educação a Distância da Universidade Federal de Uberlândia - CEaD/UFU. O artigo é organizado em torno de duas questões básicas: Existe a necessidade de formar docentes, atuantes em cursos presenciais, para atuar em EaD? Que práticas formativas podem contribuir para que o professor possa se apropriar de detalhes fundamentais para o sucesso do trabalho profissional no contexto da EaD? O estudo é resultado de uma sistematização reflexiva, em diálogo com experiências e pesquisas no contexto da formação docente, levando em conta as especificidades e os desafios da docência na $\mathrm{EaD}$. Tomando para análise a produção de professores que participaram do Curso de Formação de Professores Autores para atuar na EaD oferecido pelo CEaD/UFU em 2013 e a interação entre eles e as tutoras formadoras, serão apresentados elementos que permitem identificar as concepções que fundamentam e orientam os fazeres docentes dos educadores e suas ressignificações, apropriações e/ou
\end{abstract}

DOI: $10.1590 / 0104-4060.38658$

1 Universidade Federal de Uberlândia, Faculdade de Matemática, Programa de Pós-Graduação em Ensino de Ciências e Matemática (PPGECM/UFU) e Centro de Educação a Distância da Universidade Federal de Uberlândia (CEaD/UFU). Uberlândia, Minas Gerais, Brasil. Avenida João Naves de Ávila, 2160. CEP: 39400-902.

2 Universidade Federal de Uberlândia, Programa de Pós-Graduação em Educação da Faculdade de Educação (PPGED/FACED/UFU) e Centro de Educação a Distância da Universidade Federal de Uberlândia (CEaD/UFU). Uberlândia, Minas Gerais, Brasil. Av. João Naves de Ávila, 2121. CEP: $38400-902$. 
construção de conhecimentos decorrentes da experiência e das exigências demandadas pela EaD.

Palavras-chave: docência; educação a distância; formação de professores.

\begin{abstract}
This article is an essay that aims to problematize and discuss the challenges of providing formation for professors to be authors and formative teachers in a context of Distance Education, based on experiences and accumulated reflections of the authors in teaching and management activities in the Center of Distance Education at the Universidade Federal de Uberlândia - CEaD/ UFU. The essay is organized around two basic questions: Is it necessary to provide a formation on distance education to professors that deal with a non distance education environment? What formative practices can contribute to the teachers' appropriation of fundamental details to a well succeeded professional development in a Distance Education context? The study is a result of a reflexive systematization, dialoging with experiences and researches in the teacher training context, taking into account the challenges and particular aspects of distance education teaching. Analyzing the production of the participating professors who attended the AuthorsProfessors Training Course to perform in Distance Education, offered by $\mathrm{CEaD} / \mathrm{UFU}$ in 2013, and the interaction between them and the training tutors, elements that make possible to identify the basic and guiding conceptions of teaching performance of the educators and their resignifications, appropriations, and/or constructions of knowledge originated from the experience and requirements of Distance Education will be presented.
\end{abstract}

Keywords: teaching; distance education; professors' formation.

\title{
Introdução
}

Iniciativas envolvendo programas de Educação a Distância no Brasil não são recentes e muito se fez e ainda se tem feito para que a Educação atinja pessoas que se encontram distantes e em situações especiais. Conforme registra Preti,

[...] o Brasil vem desenvolvendo programas em EaD há décadas, alguns deles muito conhecidos, como o Movimento de Educação de Base (MEB, 
1956), projeto Minerva (1970), Logos (1977), Telecurso $2^{\circ}$ grau (1978), Mobral (1979), Um Salto para o Futuro (1991), Telecurso 2000 (1995), TV Escola (1996), PROFORMAÇÃO (1999) (PRETI, 2009, p. 29).

Embora existam registros de outras iniciativas, além das acima citadas, devemos reconhecer que a expansão da Educação a Distância no âmbito das Universidades Públicas passou a tomar forma e ter visibilidade a partir da publicação, no final do ano de 2005, do edital para a "Chamada pública para seleção de polos municipais de apoio presencial e de cursos superiores de instituições federais de ensino superior na modalidade de educação a distância para o 'Sistema Universidade Aberta do Brasil - UAB'” (BRASIL, 2005). Ainda em 2005 foi lançado o primeiro curso-piloto da UAB, o curso de Administração que se deu por uma parceria entre a Secretaria de Educação a Distância do Ministério de Educação - SEED/MEC, o Banco do Brasil e Instituições Federais e Estaduais de Ensino Superior. Inicialmente algumas universidades foram selecionadas para atendimento desta demanda $-50 \%$ das vagas seriam destinadas a funcionários do Banco do Brasil e as demais à comunidade.

A Universidade Federal de Uberlândia - UFU participou deste movimento de democratização e expansão do ensino superior e, em 2006, foi realizado o vestibular do Curso de Graduação em Administração a Distância - Projeto Piloto da UAB -, oriundo da parceria da SEED/MEC com o Banco do Brasil e Instituições Federais e Estaduais de Ensino Superior, conforme anteriormente citado. Esta iniciativa esteve sob a coordenação da Faculdade de Gestão e Negócios - FAGEN - e, à época, a UFU ainda não contava com o Centro de Educação a Distância - CEaD - para aglutinar e apoiar as ações dos cursos na modalidade a distância.

Merece salientar-se que foi em 2006 que se deu de fato a instituição da Universidade Aberta do Brasil, por meio do Decreto 5.800/06, publicado em 8 de junho. Nesta ocasião, com o início do curso piloto de Administração, já se percebia a necessidade de preparação e formação dos envolvidos na oferta de um curso oferecido na modalidade a distância, em que a mediação e interação deveriam ser cautelosamente cuidadas em busca de uma proximidade na maioria das vezes virtual. Os primeiros passos para garantir a qualidade do curso já mostravam que

[...] a organização de um sistema de Educação a Distância é mais complexa, às vezes, que um sistema tradicional presencial, visto que exige não só a preparação de material didático específico, mas também a inte- 
gração de "multimeios" e a presença de especialistas nesta modalidade. O sistema de acompanhamento e avaliação do aprendente requer também tratamento especial. Isso significa atendimento de expressiva qualidade (PRETI, 2009, p. 83).

No movimento político de expansão e interiorização do ensino no Brasil, outros cursos foram aprovados para oferta na modalidade a distância, sob a responsabilidade de diferentes unidades acadêmicas da Universidade, com apoio do Centro de Educação a Distância da UFU, que se instituiu com a nomeação de sua diretoria em 2008. Cursos de Aperfeiçoamento, Graduação, Especialização e Extensão demandavam a formação dos integrantes para lidar com os trâmites inerentes à modalidade que incluíam detalhes que iam desde a aprendizagem de trabalho em equipe e colaboração ao domínio de recursos tecnológicos e de ambientes virtuais. Arruda e Freitas (2012) percebem a EaD como precursora de impactos sociais, uma vez que, na concepção dos autores,

[...] a EaD significa mudanças mais profundas nas relações sociais estabelecidas no interior da escola e representa, dentre outras coisas, a constituição de novos agentes pedagógicos, novos papéis para o professor e, por que não, a constituição de um novo docente, com atribuições e ações bem distintas da educação dita "convencional" (ARRUDA; FREITAS, 2012, p. 17).

A constatação das ideias dos autores aliada às orientações da Coordenação de Aperfeiçoamento de Pessoal de Nível Superior - CAPES - e da Comissão Nacional de Avaliação da Educação Superior - CONAES - instigaram as Instituições de Ensino Superior - IES - a se organizarem para implantar um processo de formação dos envolvidos em cursos oferecidos na modalidade a distância, especialmente os professores e tutores. Estas iniciativas vieram sempre acompanhadas das indagações: Existe a necessidade de formar docentes, atuantes em cursos presenciais, para atuar em $\mathrm{EaD}$ ? Que práticas formativas podem contribuir para que o professor possa se apropriar de detalhes fundamentais que favorecem o processo de ensino e aprendizagem no contexto da EaD?

Parece imprescindível e inquestionável a necessidade de se aprender a lidar com o trabalho em cooperação entre diferentes profissionais de cursos oferecidos na modalidade a distância, bem como garantir a necessária sintonia e harmonia entre o professor e o tutor. Por acreditar na importância e contribuição 
da formação continuada para a prática docente, a equipe responsável pelo apoio aos cursos oferecidos na modalidade a distância do CEaD/UFU se envolveu com a elaboração de uma proposta de processos formativos tanto de professores quanto dos outros atores participantes. A formação continuada de professores, nas palavras de Imbernón, deve "fomentar o desenvolvimento pessoal, profissional e institucional do professorado, potencializando um trabalho colaborativo para mudar a prática" (IMBERNÓN, 2009, p. 49).

O movimento instaurado com a pequena equipe de professores e técnicos atuantes no $\mathrm{CEaD} / \mathrm{UFU}$ trazia para o contexto a preocupação de se conhecer, reconhecer e respeitar a relação dos diferentes professores da instituição com as práticas de leitura e escrita digital e dos processos de aprendizagem em tempos de inovação tecnológica. Havia, sem dúvida, a necessidade de encontrar caminhos que provocassem reflexões sobre os desafios apresentados pelos recursos que a cibercultura nos apresenta e os reflexos desta realidade na tarefa de ensinar e no processo de aprender, seja em uma modalidade presencial ou a distância. Houve, então, o empenho em elaborar uma proposta que fosse atraente o suficiente para provocar nos envolvidos a vontade de interagir e conhecer as especificidades de uma docência compartilhada e colaborativa, como também de investigar e criar possibilidades de potencializar os recursos que um ambiente virtual oferece, mas não só isso seria suficiente. O professor haveria de conhecer as especificidades que envolvem o contexto educacional nacional e os meandros que circundavam um curso oferecido na modalidade a distância em que

os papéis de professor e de alunos podem se fundir para se autoconstruírem, na medida em que se auto-organizam à luz das aprendizagens emergentes. Dessa relação se constituem parcerias, nas quais todos aprendem a trabalhar colaborativamente (BRUNO, 2009, p. 99).

Entre outros percalços a serem superados, havia a necessidade de incluir na formação do professor da academia, que assumiria turmas em cursos a serem oferecidos na modalidade a distância, a presença, o papel, os limites e a importância do tutor neste contexto. Desta forma cuidadosamente foram selecionados professores-tutores para atuarem nos cursos de formação continuada oferecidos pelo $\mathrm{CEaD/UFU} \mathrm{que} \mathrm{teriam,} \mathrm{entre} \mathrm{outros} \mathrm{papéis,} \mathrm{a} \mathrm{missão} \mathrm{de} \mathrm{sensibilizar} \mathrm{os}$ professores participantes a respeito do alcance e dos limites de sua atuação. Seria necessário que o professor tivesse a oportunidade de conhecer os fundamentos e a gestão da Educação a Distância e ainda como se deu a história e a organização da Universidade Aberta do Brasil e de outras iniciativas do governo de 
legislar sobre a oferta de cursos na modalidade EaD. Para além de questões de cunho teórico, seria também imprescindível disparar momentos que instigassem reflexões sobre a linguagem mais apropriada para lidar em ambientes virtuais e a especificidade da escrita de um material didático para atingir os alunos que, embora sejam alunos da instituição com mesmos direitos e deveres, encontram-se na maioria do tempo em outros espaços diferentes da tão conhecida sala de aula. Haveria, assim, a necessidade de instaurar momentos de reflexão profícua que instigassem o pensar e a criação de estratégias e meios de minimizar as distâncias potencializando ações interativas propiciadas pelo avanço tecnológico. Freitas (2013) observa ser este movimento necessário e característico de uma mudança paradigmática percebida em diferentes contextos pela prosperidade do conhecimento tecnológico. A autora argumenta que:

[...] as transformações paradigmáticas não são de fácil operacionalização e nada acontece por legislação ou imposição. Entretanto, já se percebe entre os docentes a existência de uma sensibilidade para a percepção sobre o paradigma que surge e isso os leva a buscar o novo e a ansiar por rupturas e por desmistificação de utopias no intuito de encontrar caminhos que possibilitem fazer melhor o que antes já se acreditava fazer tão bem [...] (FREITAS, 2013, p. 201).

Havia uma hipótese inicial na proposta de formação do CEaD/UFU de que os professores participantes do Curso de Formação teriam alguma familiaridade com a cultura digital e, desta forma, a proposta pleiteava fornecer espaços propícios de interação entre professores e tutores formadores que favorecessem as relações interpessoais tão necessárias para a realização de aprendizagem, levando-se em conta os estudos de Vygotsky (1991).

Além da presença da teoria social da construção do conhecimento de Vygotsky, percebe-se neste contexto indícios da teoria enunciativa da linguagem de Bakhtin (1986, 2000), pois embora Bakhtin tenha desenvolvido seus estudos em uma época em que a possibilidade de interações em espaços virtuais fosse inimaginável, seus estudos podem contribuir com a realidade da educação a distância, pois pela linguagem é que se comunica via internet, em outro espaço, também de cunho social. Parece importante atentar neste contexto para as palavras de Freitas (2009), quando argumenta que no ciberespaço o homem perde indícios de materialidade "preservando, no entanto, toda a riqueza e complexidade das múltiplas formas de expressão de linguagem" (FREITAS, 2009, p. 63). 
Neste sentido, a equipe do $\mathrm{CEaD/UFU} \mathrm{planejou,} \mathrm{além} \mathrm{da} \mathrm{formação} \mathrm{de}$ tutores para atuar na $\mathrm{EaD}$, um curso destinado a capacitar docentes para atuarem na elaboração de materiais didáticos e de atividades de orientação à tutoria em cursos oferecidos pela Universidade Federal de Uberlândia na modalidade a distância. O pressuposto básico desta formação é que, na $\mathrm{EaD}$, o material didático assume o papel de fio condutor, pois organiza o desenvolvimento e a dinâmica de todo o processo de ensino e aprendizagem. Assim, espera-se que o professor, na elaboração deste, valorize atividades e leituras que dialoguem com as vivências dos alunos/profissionais e tenha a preocupação de, mais do que apresentar uma grande quantidade de conteúdos, oferecer referenciais teóricos e estratégias metodológicas em uma perspectiva interativa que motive o aluno à busca e apropriação crítica de conhecimentos disponibilizados em diferentes fontes e o estimule a realizar suas atividades com envolvimento, possibilitando, assim, o desenvolvimento de competências pessoais e profissionais.

Estruturado em 100 horas, o curso de formação de professores autores para atuar em cursos de EaD da UFU divide-se em oito horas presenciais e 92 horas a distância. A parte presencial é realizada em dois encontros de quatro horas cada: um ao início, para apresentar a equipe, cronograma, plano do curso e iniciar o acesso ao Moodle, e outro ao final do curso, para sintetizar os estudos, sanar dúvidas e levantar sugestões. A programação a distância é desenvolvida no ambiente Moodle por meio da leitura de textos e realização de atividades elaboradas por profesores do $\mathrm{CEaD/UFU}$ que coordenam a mediação pedagógica realizada por tutoras formadoras vinculadas ao Centro, que atendem a uma média de 15 cursistas, com o apoio do setor de Tecnologia da Informação, que organiza o Ambiente Virtual de Aprendizagem - AVA 3 .

As 92 horas a distância são divididas em 5 módulos, com duração de uma semana ou 15 dias cada, conforme a quantidade e os tipos de atividades: I - Educação a Distância: fundamentos e desenvolvimento; II - Planejamento e gestão da Educação a Distância; III - Produção de material didático em diferentes suportes midiáticos; IV - Avaliação da aprendizagem na Educação a Distância; V - Atuação do professor formador no curso e na tutoria. Além das leituras e debates sobre as temáticas de cada módulo, são realizadas atividades práticas de ambientação no Moodle, planejamento de disciplina (agenda, objetivos, distribuição do conteúdo, procedimentos avaliativos, etc.), elaboração de material didático/atividades para uma unidade de ensino, de chave de correção e orientações para tutores. Por meio destas atividades, os professores experimentam diferentes recursos que poderão utilizar em suas disciplinas, como postagem

3 Para conhecer o Moodle do CEAD/UFU, acessar: < http://www.cead.ufu.br/>. 
de tarefa, fóruns de discussão, wikis, chats, elaboração de glossários, resposta a questionários fechados e enquetes.

De setembro de 2010 a dezembro de 2013, foram oferecidas oito edições do curso para docentes inscritos conforme solicitação de Unidades Acadêmicas da UFU que planejavam iniciar cursos na modalidade a distância, totalizando 299 professores, dos quais 215 concluíram o curso e estão envolvidos na oferta de cursos de graduação (Administração Pública, Pedagogia, Letras-Inglês, Letras-Espanhol, Matemática), aperfeiçoamento (Educação Especial, Educação Especial para Alunos Surdos, Educação para as Relações Étnico-Raciais, Ensino de Língua Brasileira de Sinais - Libras, Linux e LibreOffice), especialização (Gestão Pública, Gestão Pública Municipal, Gestão em Saúde, Mídias na Educação) e extensão (Programa de Fortalecimento dos Conselhos Escolares, Programa de Apoio aos Dirigentes Municipais de Educação).

Conforme revela a avaliação do curso realizada ao final de cada edição pelos professores cursistas, este contribuiu para que eles que, majoritariamente, tinham uma trajetória de formação e atuação na educação presencial, iniciassem ou aprofundassem o seu contato com a educação a distância, minimizando resistências e auxiliando no planejamento da disciplina que ofereceriam no curso $\mathrm{EaD}$ em que atuariam. As principais ressalvas dos cursistas referem-se à falta de tempo para interagirem mais entre si, a necessidade de explorarem mais os recursos do Moodle e conhecerem mais detalhadamente o processo de produção de vídeoaulas, o que a equipe do $\mathrm{CEaD/UFU} \mathrm{tem} \mathrm{procurado} \mathrm{atender} \mathrm{por} \mathrm{meio}$ da oferta de cursos de formação continuada para tutores e professores de $\mathrm{EaD}$ que já concluíram a formação inicial.

Para refletirmos mais detalhadamente sobre os desafios de formar-se professor formador e autor na Educação a Distância, analisaremos produções e interações dos cursistas e tutores formadores da oitava edição do Curso de Formação de Professores Autores para atuar na EaD, oferecido pelo CEaD/UFU entre os meses de novembro e dezembro de 2013. Serão apresentados elementos que permitem identificar os saberes e práticas que fundamentam e orientam os fazeres docentes dos educadores e suas ressignificações, apropriações e/ ou construção de conhecimentos decorrentes da experiência e das exigências demandadas pela EaD. Mas antes, para compreendermos o contexto de construção das produções e interações que serão analisadas, é importante conhecer o perfil de quem as produziu.

A oitava edição do curso foi formada por duas turmas compostas por nove cursistas cada, acompanhados por tutoras formadoras que atuam na EaD/ UFU desde seu início, tanto na formação de tutores e professores, quanto na coordenação de tutores de cursos a distância. Constituía-se em um grupo bastante heterogêneo, formado por docentes de diferentes unidades acadêmicas 
da UFU - Faculdade de Gestão e Negócios, Faculdade de Ciências Contábeis, Faculdade de Matemática, Instituto de Letras e Linguísticas -, responsáveis pelos cursos a distância em Administração Pública, Licenciaturas Letras-Espanhol e Matemática e Especialização Educação Especial - Libras e Altas Habilidades. Alguns haviam iniciado sua carreira universitária há seis meses e outros já tinham mais de 25 anos de atuação. Eram doze doutores, quatro mestres, dois especialistas, formados em diferentes áreas: Comunicação Social, Direito, Ciências Contábeis, Ciências Econômicas, Administração, Ciências da Computação, Informática, Engenharia Elétrica, Matemática, Ciências Biológicas e Letras - Português-Espanhol.

Sobre a sua relação com o computador e a Internet, confirmando a hipótese inicial de que os professores participantes do Curso de Formação teriam alguma familiaridade com a cultura digital, todos afirmaram utilizar vários recursos, com menor ou maior facilidade, mas seis deles não conheciam o Moodle - plataforma utilizada pela UFU para seus cursos a distância. Sobre a experiência profissional em cursos de EaD, conforme o Gráfico 1 apresentado a seguir, mais da metade não a possuía. Dois participantes já tinham atuado como tutores e cinco já haviam atuado como docentes, sendo que dois deles já tinham produzido material didático. Outros dois cursistas também já tinham sido alunos de cursos a distância.

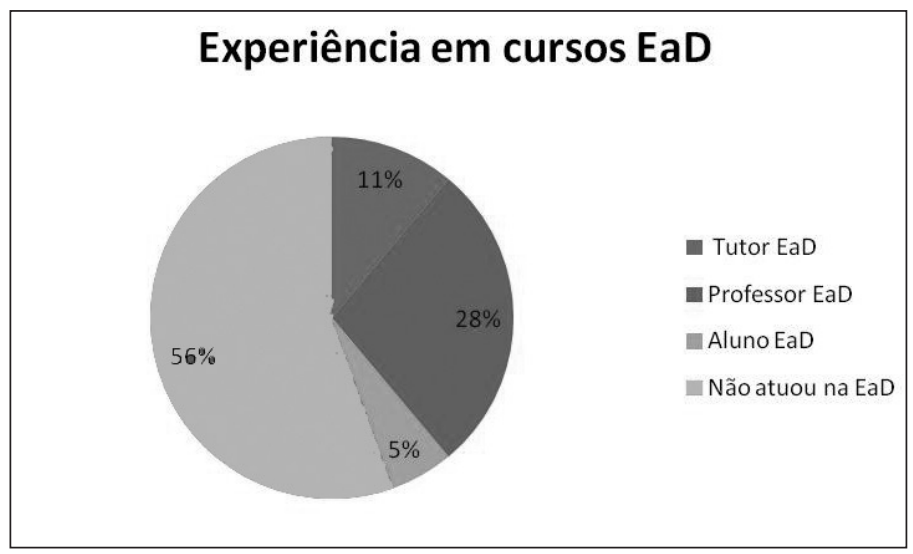

GRÁFICO 1 - EXPERIÊNCIA EM CURSOS EaD DOS PROFESSORES CURSISTAS DA OITAVA EDIÇÃO DO CURSO DE FORMAÇÃO DE PROFESSORES AUTORES PARA ATUAR NA EaD - CEaD/UFU, 2013.

FONTE: Enquete respondida, em novembro de 2013, pelos professores cursistas da oitava edição do Curso de Formação de Professores Autores para atuar em EAD - CEAD/UFU. Disponível em: $<$ https://www.ead2.ufu.br/mod/feedback/analysis.php?id=4351\&courseid=\&do_show=analysi $>$. Acesso em: 15 dez. 2013. 
Em síntese, os professores cursistas, mesmo aqueles que já haviam tido experiência em cursos a distância, construíram suas práticas docentes em formações presenciais, desde saberes acumulados na vida escolar, até saberes profissionais e disciplinares adquiridos na universidade e saberes experienciais constituídos na relação presencial professor-aluno. Profissionais, então, que ao iniciarem seu trabalho em cursos a distância, enfrentam o novo em uma função que já exercem há tempos, estranham o que já dominam. Conforme Oliveira e Sobrinho:

As experiências do professor autor como docente no ensino presencial devem ser consideradas como constantes referências para utilização na $\mathrm{EaD}$, e não este procurar simplesmente transpor suas experiências do ensino presencial para a modalidade a distância, pois, cada uma possui suas peculiaridades e necessidades específicas, porém estas só serão supridas e identificadas com o tempo de atuação do professor na modalidade a distância (OLIVEIRA; SOBRINHO, 2010, p. 11).

Uma das principais necessidades específicas da construção do processo de ensino e aprendizagem na educação a distância é, conforme Zuin, "fornecer condições para que os professores ausentes se tornem presentes" (ZUIN, 2006, p. 948). A dificuldade em lidar com a "ausência" do professor mantém-se mesmo entre alunos que já estudam em cursos EaD há algum tempo. Evidências disto estão registradas em dados coletados, no final de 2012, durante avaliação realizada entre estudantes do curso de Pedagogia a distância da UFU iniciado no segundo semestre de 2009 (turma 1) e no segundo semestre de 2011 (turma 2). Muitos alunos destacam a necessidade do contato direto com o professor, através de encontros presenciais periódicos para que alunos conheçam pessoalmente tutores e professores e possam trocar experiências, ou de interação direta entre professores e alunos no AVA, ou ainda de vídeoaulas mais dinâmicas que não sejam mera reprodução do que está escrito no guia impresso. Estudantes que preencheram a avaliação registraram:

Acredito que a nossa dificuldade é a distância, às vezes temos questões que fazemos um esforço muito grande por falta de uma luz do professor, uma aula por semana nos ajudaria muito, como ocorre em alguns cursos a distância... (aluno 50 - turma 2 do curso de Pedagogia a Distância oferecido pela Faculdade de Educação da UFU, grifo nosso). 
As videoaulas precisam ser mais atrativas, contendo mais comentários e opiniões dos professores, porque eles não falam nada além do que está no guia impresso e se mostram muito distantes dos alunos (aluno 40 turma 2 do curso de Pedagogia a Distância oferecido pela Faculdade de Educação da UFU, grifo nosso).

Como podemos perceber nestes depoimentos, o professor torna-se uma autoridade imagética, uma entidade coletiva considerada, na maioria das vezes, inatingível e espetacular, detentora de um conhecimento absoluto e indiscutível. Segundo Zuin:

O risco da chamada transformação do professor numa entidade coletiva [...] é o de pulverizar a autoridade de tal professor a ponto dela se rearticular na forma do autoritarismo imagético que arrefece o desenvolvimento das representações e, portanto, do raciocínio crítico (ZUIN, 2006, p. 949).

Como contraponto a este risco, Zuin (2006), aproximando-se indiretamente da teoria enunciativa da linguagem de Bakhtin abordada anteriormente, sugere romper com o distanciamento professor-aluno através do uso dos aparatos técnico-eletrônicos para criar mediações pedagógicas interativas, questionadoras, reflexivas que rompam com o processo de fetichização e transformem os estudantes em sujeitos, interventores de suas ações:

[...] não seria possível que os mestres ausentes utilizassem os aparatos técnico-eletrônicos para poder criticar e tensionar o próprio autoritarismo de sua imagem e, assim, pudessem se tornar mais presentes? Penso que sim. Mas, para que o conhecimento produzido seja discutido e modificado coletivamente, é necessário que a autoridade pedagógica seja "superada", o que não significa a sua eliminação. Quando os alunos percebem que suas opiniões são respeitadas pelos mestres, inicia-se o processo de superação da autoridade pedagógica, pois as explicações dos professores se conservam modificadas nas intervenções do corpo discente (ZUIN, 2006, p. 951).

São estas e outras possibilidades de enfrentar os desafios advindos das peculiaridades e necessidades específicas da $\mathrm{EaD}$ que vamos analisar a seguir na experiência formativa de professores universitários para atuar em cursos a 
distância. Para isto, vamos centrar nossas análises em duas dimensões que, a nosso ver, contribuem para "tornar presente o professor ausente": primeiramente, a relação entre professores autores/formadores e tutores $\mathrm{EaD}$, e depois, a relação entre equipe docente, alunos $\mathrm{EaD}$, aparatos técnico-eletrônicos e conhecimentos, como destacado por Zuin.

Nos cursos a distância, o professor se faz presente por meio da polidocência, ou seja, ele não estabelece relação direta com os alunos, mas via tutores e material didático impresso, audiovisual e/ou digital. Assim, ao se formar professor autor/formador, o docente deve reconhecer a necessidade de planejar e acompanhar suas aulas em equipe, junto a profissionais das áreas de webdesign e de tecnologia da informação e de tutores. Precisa participar da formação de tutores que, como responsáveis pelo contato mais próximo e frequente com os alunos, contribuam para que estes interajam criticamente com o conhecimento e com seus colegas. Além disso, precisa ter disponibilidade para observar ativa e assiduamente o desenvolvimento de seu curso no AVA, atento à emergência da necessidade de criar novas orientações para os tutores, de elaborar atividades complementares a tempo de trabalhar lacunas e dificuldades não previstas no ato de planejar a disciplina.

Nos registros das interações e produções construídas ao longo da oitava edição do Curso de Formação de Professores Autores do CEaD/UFU, que deste ponto em diante será identificada como FPAEAD-T8, o desafio de tornar os professores presentes através da figura dos tutores manifestou-se, principalmente, no módulo 4, Avaliação da Aprendizagem na Educação a Distância, nas atividades de elaboração do mapa da disciplina (distribuição do conteúdo por módulos e atividades, planejamento de avaliação, orientação aos tutores para encaminhar o trabalho) e das chaves de correção das atividades avaliativas. Nas atividades postadas e no fórum de discussão, evidenciou-se um "nó" na relação professor-tutores-alunos-conhecimentos importante de se desatar.

$\mathrm{Na}$ divisão de trabalho entre professor e tutor, existe a necessidade de o primeiro delimitar a atuação do segundo para que todas as turmas do curso, mesmo que atendidas por tutores diferentes, alcancem formação semelhante e sejam avaliadas da maneira mais uniforme e coerente possível. Mas como combinar esta necessidade com a defesa de que a educação a distância rompa com a "perspectiva instrucionista" de aproveitar as potencialidades dos recursos tecnológicos para simplesmente armazenar, transmitir e registrar informações especializadas, e se molde com base na "perspectiva construcionista", que beneficia a autoaprendizagem e a interaprendizagem? Conforme Masetto, a perspectiva construcionista incentiva 
a participação e o envolvimento do aprendiz, o intercâmbio de informações, de diálogo e de debate entre os participantes, uma utilização de técnicas e máquinas que permita visualizar um problema, sua possível solução, discutir o processo, analisar criticamente a solução desenhada, verificar se ela atendeu o esperado, revê-la à luz de outras informações e ideias novas, registrar e documentar a experiência, comunicar-se sobre ela, analisá-la e criticá-la (MASETTO, 2013, p. 165).

Como conciliar, então, a necessidade de padronizar a atuação dos tutores através da ação dos professores autores/formadores, com o desejo de delinear um curso a distância que se desenvolva através da atuação autônoma e criativa do tutor no contato direto com alunos na construção do conhecimento? Como afirma Zuin:

O tutor não pode simplesmente absorver os conhecimentos transmitidos pelos professores, quer seja nos encontros presenciais esporádicos entre ambos, quer seja no sortilégio que as imagens de tais mestres "virtuais" possam exercer. Ele deve se permitir, cada vez mais, ousar saber, o que implica não a aceitação passiva dos conhecimentos obtidos (ZUIN, 2006, p. 949).

Seria necessário que o professor autor/formador estabelecesse esta relação construcionista com os próprios tutores, no ato de orientá-los sobre a utilização do material didático e das chaves de correção das atividades, durante o desenvolvimento do curso.

Na FPAEAD-T8, encontramos registros desta complexa equação. No feedback que as tutoras formadoras redigiram para a chave de correção elaborada pelos professores cursistas, elas destacaram, várias vezes, a necessidade dos mesmos indicarem questões e apontamentos para auxiliar os tutores na mediação dos fóruns de discussão, bem como de relacionarem mais detalhadamente os critérios de correção com a pontuação, evitando subjetividades e colocações muito abertas. Feedbacks como:

É preciso que os critérios de avaliação sejam bem detalhados e claros para que o tutor não faça nada inadequado. Explique ao tutor que tipo de comentário ele deve fazer sobre as postagens dos alunos e como deverá valorizar as produções dos alunos. [...] Sugiro que você explique melhor 
FREITAS, M. T. M.; FRANCO, A. P. Os desafios de formar-se professor formador...

ao tutor que tipo de comentário ele deve fazer sobre as postagens dos alunos nos fóruns. É interessante lançar algumas questões para ele postar durante a discussão no fórum como intuito de instigar a participação (tutora formadora 1, FPAEAD-T8, CEaD/UFU, 2013).

Uma das cursistas elaborou a seguinte chave de correção:

1. Esta questão é aberta e não há uma resposta totalmente correta. Os alunos deverão ler as histórias de vidas e sucesso de dois empreendedores e comparar quais características são comuns a eles; 2. Assim como a primeira questão, não há uma única resposta. O importante é elencar o que os diferencia. A chave é perceber que não existem características únicas que levam ao sucesso. 3. Nesta questão, os alunos ao invés de elencar características pessoais, deverão falar das atitudes como profissionais. As respostas também variarão, dado que eles podem escolher diferentes pessoas para suas análises (professora cursista 1 - FPAEAD-T8, CEaD/ UFU, 2013).

Em resposta, a tutora formadora escreveu:

Para evitar a subjetividade na correção por parte dos tutores, sugiro uma resposta contendo todos os elementos necessários que sirva como parâmetro. Além disso, a distribuição de pontos para cada elemento cobrado na questão facilita muito a avaliação (tutora formadora 2, FPAEAD-T8, $\mathrm{CEaD} / \mathrm{UFU}, 2013)$.

Nesta construção, a professora autora destacou, na chave de correção, a importância do tutor perceber e valorizar múltiplas possibilidades de reflexão frente à situação-problema colocada:

Escolha dois dos sete casos apresentados e responda às seguintes questões: 1. Quais características estes empreendedores apresentam em comum?; 2. Em que ponto eles divergem?; 3. Quais atitudes foram fundamentais para que fossem homens de sucesso?; 4. Qual é a importância de se ter pessoas desse tipo na economia? 
No feedback sobre esta chave de correção, a tutora formadora destacou a importância de serem apresentados para o tutor alguns parâmetros para auxiliá-lo na avaliação das reflexões dos alunos. Apresenta-se aí um grande desafio: o equilíbrio entre a abertura para um processo avaliativo que não bloqueie a possibilidade de construção de respostas que demonstrem o processo de apropriação crítica do conhecimento pelos alunos, que não transforme o tutor em mero aplicador de gabaritos, e a necessidade de princípios para se verificar com coerência a argumentação de alunos de diferentes turmas/tutores.

Neste mesmo sentido, outra professora cursista que já tivera experiência em EaD, elaborando chaves de correção e validando o trabalho de correção de provas realizado pelos tutores, afirma que "por mais que explicamos como deve ser feita a correção, ainda é muito difícil que pensemos da mesma maneira" (professora cursista 2 - FPAEAD-T8, CEaD/UFU, 2013).

No debate sobre estes desafios no fórum sobre correção de atividades, um professor da área de Matemática, que também já havia participado da preparação de tutores para correção de atividades avaliativas, faz um relato que registra a preocupação com a formação do tutor, que precisa dominar o conteúdo ministrado e o uso de chave de correção que aponta a necessidade de se valorizar a produção e o raciocínio de cada aluno, além da disponibilidade para auxiliar o tutor durante a atividade de correção.

[...] tivemos como atividade a ser entregue uma lista com 16 exercícios. [...] a correção das listas foi feita por tutores que foram previamente instruídos quanto à chave. Esses tutores são graduados em Matemática (portanto conhecem bem o conteúdo da matéria). As instruções foram passadas via webconferência e, é claro, também por e-mail. A principal instrução foi que considerassem qualquer forma de raciocinio parcialmente correto que o aluno pudesse apresentar. Uma questão entregue pelo aluno não geraria pontos apenas se estivesse totalmente errada, sem absolutamente nada que pudesse ser aproveitado para uma possivel resolução correta. Casos duvidosos foram resolvidos com o auxílio dos professores da disciplina (professor cursista 3 - FPAEAD-T8, CEaD/ UFU, 2013).

Ao acompanhar este debate, uma professora cursista que ainda não tinha experiência em $\mathrm{EaD}$, mas foi uma das que, durante o curso, mais interagiu com seus colegas e tutora, preocupando-se em conhecer experiências e trocar ideias, transferiu esta prática ao ensaiar a elaboração de uma chave de correção: 


\begin{abstract}
Caro Tutor,
A avaliação de cada exercício deve levar em conta o raciocínio do aluno e de que forma ele(a) chega a suas conclusões.

Cada erro leve de raciocínio ou de aritmética (como um sinal ou uma soma errada) é descontado $11 \%$ do valor do exercício.

Contradições de raciocínio ou conclusões não interligadas devem ser tratadas como "erro grave" e descontado $101 \%$ do valor do exercício.

Caso em que o raciocínio do aluno não esteja claro, mas há a impressão que o aluno tem a ideia correta, coloque o sinal de interrogação à questão, dando oportunidade ao aluno de defender a sua ideia. É no fórum que o aluno tem a oportunidade de melhor se explicar.

Decida então se a explicação é satisfatória para revisar o valor final do exercício.

A seguir são dadas as dicas da solução para o exercício.

Qualquer dúvida, não hesite em me enviar um email. Podemos usar o ambiente do chat do Moodle para resolver dúvidas de alunos ou as suas. Basta combinar dia e horário.

Bom trabalho e estou à disposição!

(professor cursista 4 - FPAEAD-T8, CEaD/UFU, 2013)
\end{abstract}

Além de detalhar os procedimentos de pontuação dos exercícios, a professora ressalta para o tutor que "a avaliação de cada exercício deve levar em conta o raciocínio do aluno e de que forma ele(a) chega à suas conclusões", demonstrando a preocupação em desenvolver um processo de ensino e aprendizagem construcionista. A mesma é reforçada quando ela sugere que o tutor, além de corrigir o exercício de seus alunos, aponte partes que não ficaram muito claras, dando a chance para os alunos reverem seu raciocínio e tendo flexibilidade para revisar a nota: “... Caso em que o raciocínio do aluno não esteja claro, coloque o sinal de interrogação [...] dando oportunidade ao aluno de defender a sua ideia. É no fórum que o aluno tem a oportunidade de melhor se explicar. Decida então se a explicação é satisfatória para revisar o valor final do exercício".

No que tange à relação professor-autor e tutor, a professora cursista revelou sua intenção em manter diálogo aberto com os tutores para acompanhá-los em sua tarefa, ao finalizar a chave de correção com os dizeres: "Qualquer dúvida, não hesite em me enviar um email. Podemos usar o ambiente do chat do Moodle para resolver dúvidas de alunos ou as suas. [...] Estou à disposição!". Além disso, enquanto apresentava "as dicas da solução para o exercício", a tutora mantinha o diálogo com o tutor, ao escrever "Caro tutor: concorda com o que fizemos até aqui? Aguardo retorno!".

Sobre essa primeira dimensão que nos propusemos a abordar no presente ensaio, a relação entre professores autores/formadores e tutores $\mathrm{EaD}$, finaliza- 
mos nossas reflexões sintetizando que, no desenvolvimento de cada disciplina, por meio da dinâmica da polidocência, o professor "ausente" se faz presente, através de professores, tutores e alunos, no ato coletivo de trocar saberes e práticas, negociar e compartilhar decisões, buscar consensos, sob a coordenação do professor autor.

A seguir, vamos abordar a segunda dimensão de nossas análises: a relação entre equipe docente, alunos $\mathrm{EaD}$, aparatos técnico-eletrônicos e conhecimentos.

Para aproximar alunos e professores que comumente não se encontram fisicamente no espaço da sala de aula, o professor autor, ao elaborar o material didático de sua disciplina, precisa antecipar dúvidas dos alunos, prever estratégias para diálogo sem conhecer de antemão seus interlocutores, lançar perguntas orientadoras, propor situações-problema que relacionem a aprendizagem com a realidade social, as experiências e saberes dos alunos, incentivar a crítica quanto à quantidade e qualidade de informações que se dispõe. Enfim, desenvolver linguagem própria para $\mathrm{EaD}$ que possibilite interação e comunicação dialógica entre tutores e alunos, alunos e alunos, e não fique restrita à linguagem acadêmica, ou, no outro extremo, caia no tecnicismo, na reprodução sem reflexão. Cortelazzo, ao analisar a atuação de professores autores e tutores em EaD, aponta que

A autoria do professor é um longo processo e precisa ser cuidadosamente planejado, organizado e gerenciado. Alguns professores escreveram livros para alunos de graduação em níveis altamente científicos, como se estivessem dando uma palestra a seus pares em congressos e conferências. Evidente que a educação superior exige leitura, mas os alunos precisam ser orientados a desenvolver o prazer da leitura, de forma dialógica. Dialógico não significa escrita simplória nem superficial. Discurso acurado, perguntas antecipando dúvidas dos alunos, relatos de histórias, "casos", para ilustrar conceitos, debates dos prós e dos contras e estímulos à pesquisa prendem a atenção dos alunos e os instigam à leitura e à pesquisa (CORTELAZZO, 2008, p. 319).

$\mathrm{O}$ material didático elaborado pelo professor autor em $\mathrm{EaD}$, mais do que um tratado sobre o tema em questão, é um guia de acesso, discussão coletiva e apropriação crítica dos conhecimentos acumulados sobre este tema e, neste sentido, a linguagem digital dos hipertextos muito colabora. Conforme Behrens,

[...] o professor [...] precisa levar em consideração que a tecnologia digital possibilita o acesso ao mundo globalizado e à rede de informação dispo- 
nível em todo o universo. A sala de aula passa a ser um locus privilegiado como ponto de encontro para acessar o conhecimento, discuti-lo, depurá-lo e transformá-lo (BEHRENS, 2013, p. 81).

Para alcançar estas qualidades, o professor autor precisa conhecer as especificidades e potencialidades dos aparatos técnico-eletrônicos, dos recursos digitais e midiáticos que possibilitam a produção deste material dialógico. No desenvolvimento do curso FPAEAD-T8, foi possível perceber os desafios de gerar estes conhecimentos e habilidades.

Sobre a exploração dos recursos do Moodle, além da própria dinâmica do curso possibilitar que os professores cursistas conheçam e explorem suas potencialidades através de atividades diversificadas como fóruns de dúvida, chats, elaboração coletiva de glossários, wikis, postagem de tarefas ou leitura de texto acompanhada de fóruns de discussão, as tutoras formadoras destacam, nos enunciados das atividades e na interação dos fóruns, a importância dos professores, no planejamento das disciplinas, variarem atividades e recursos, considerando o perfil dos alunos:

Acredito que este curso lhe dará muitas ideias para aprimorar este material. É preciso torná-lo mais interativo utilizando recursos midiáticos como: material impresso, audiovisual e hipermidiático.[...] É interessante que você diversifique as atividades utilizando os diferentes recursos disponiveis no Moodle: glossário, chats, fóruns, diálogo... No módulo 1 do guia você tem acesso aos diferentes tipos de atividades disponiveis no Moodle (Tutora formadora 2, FPAEAD-T8, CEaD/UFU, 2013).

Também houve a preocupação de diferenciar os recursos disponíveis, mostrando a adequação deles para cada dinâmica de ensino e aprendizagem:

[...] atividade glossário é melhor para trabalhar com conceitos. [...] Por exemplo: ao trabalhar alguns conceitos da álgebra você pode utilizar o glossário. Pode agendar um chat para o tutor tirar dúvidas dos alunos, dentre outras. [...] Quando o objetivo da atividade proposta é que os alunos postem as dúvidas relacionadas aos autores, o fórum é uma boa opção. Que tal você propor um fórum único lançando algumas questões relacionadas às ideias dos autores, solicitando comparações elou diver- 
gências de pensamentos para promover o debate? (Tutora formadora 2, FPAEAD-T8, CEaD/UFU, 2013).

Preocupada com a construção de um processo de ensino e aprendizagem que contribua para o envolvimento e diálogo dos alunos, a tutora formadora apresenta o seguinte feedback para uma unidade de ensino planejada por uma professora cursista:

Seu planejamento ficou bastante coerente. A distribuição do conteúdo não sobrecarrega o aluno, segundo meu ponto de vista. A apresentação da metodologia está condizente com a construção da aprendizagem reflexiva que se espera por parte do aluno. Quanto às atividades, sugiro a elaboração de wiki (texto coletivo) por parte dos alunos, pois ela requer a interação constante e possibilita avaliar se o trabalho foi realizado coletivamente (Tutora formadora 1, FPAEAD-T8, CEaD/UFU, 2013).

Também tem o cuidado de alertar a professora cursista para considerar os diferentes perfis de alunos, desde aqueles que acessam a Internet diariamente, até aqueles que precisam ir ao polo, muitas vezes distante de casa e do trabalho, para acessar a web:

É importante mencionar que você insere opções tais como o hipertexto e links para atividade. Isso é interessante, mas temos que tomar cuidado com o público que iremos trabalhar. Elaborar atividades que dependam de links pode comprometer a sua realização pelo fato de que nem todos terão condições de acessar diariamente o ambiente (Tutora formadora 1, FPAEAD-T8, CEaD/UFU, 2013).

O processo de elaboração e reelaboração de uma unidade de ensino por parte de um professor cursista que nunca tenha tido experiência com EaD e nem conheça a plataforma Moodle demonstra como o curso de formação para atuação em EaD é importante mesmo para aqueles professores com uma sólida trajetória na educação presencial.

Na primeira produção do professor, ele elabora um texto, no qual não há nenhum diálogo com o aluno, mas apenas a apresentação do conteúdo, através de um texto dissertativo e da sugestão, através da indicação de link, de um 
vídeo do Portal Curtas para complementar o conteúdo. O texto apresentado já se inicia com a veiculação dos objetivos da unidade e a exposição do conteúdo:

\section{Constituição}

1.1 Conceito, classificação e poder constituinte

1.2 Supremacia da Constituição e controle de constitucionalidade

1.3 As Constituições brasileiras. A Constituição vigente

O que é constituição?

No ambiente jurídico, constituição [...]

Atividade:

A propósito da proteção constitucional dos direitos humanos, assista ao vídeo "Direitos Humanos, a exceção e a regra" no link a seguir: http://portacurtas.org.br/filme/? name $=$ direitos humanos a excecao e a regra [...]

Atividade:

Leia os artigos $5^{\circ}$ (DOS DIREITOS E DEVERES INDIVIDUAIS E COLETIVOS) e $7^{\circ}$ (DOS DIREITOS SOCIAIS) da Constituição brasileira de 1988, assinalando cinco direitos que você considera como os mais importantes, em cada um dos artigos. A seguir, explique em poucas palavras porque você considera cada um deles como muito importante. Acesse a Constituição nesse link: http://www.planalto.gov.br/ccivil 03/ constituicao/constituicao.htm.

(Professor cursista 5 - FPAEAD-T8, CEaD/UFU, 2013)

Observa-se que, ao propor a atividade de pesquisa na Constituição, o professor não indica através de quais recursos do Moodle o aluno acessaria o material, postaria a produção, e nem sugere nenhuma interação com o tutor ou os colegas. Enfim, o professor ainda não dominava a possibilidade e necessidade de relacionar o material didático produzido e o AVA.

A tutora formadora, no seu feedback, procura dar dicas para tornar o material mais dialógico:

Era bom que uma breve apresentação da unidade fosse feita. Nesta apresentação os objetivos da unidade são descritos e isso facilita a orientação para o aluno. Não precisa ser algo muito complexo, mas que ajude a 
entender como funcionará a dinâmica da unidade de ensino e aonde se deseja chegar (Tutora formadora 1, FPAEAD-T8, CEaD/UFU, 2013).

E nos fóruns de discussão, por meio de comentários socializados sobre produção de outros professores cursistas, a tutora formadora ainda sugere:

Quanto à metodologia, entendo que, discussões em fóruns apareçam como atividades práticas. Todas as atividades desenvolvidas dentro do Ambiente Virtual de Aprendizagem (AVA) são como atividades desenvolvidas dentro de uma sala do ensino presencial, pois, o AVA é a sala de aula (virtual) (Tutora formadora 1, FPAEAD-T8, CEaD/UFU, 2013).

Também aproveitou a produção de um professor cursista que já tinha experiência como docente em cursos $\mathrm{EaD}$ para destacar a importância do uso de ícones que levem a interação entre o aluno e o material didático.

O professor cursista, na atividade de planejamento de uma unidade de ensino, postou:

Olá alunos, sejam bem vindos ao curso de Administração e à disciplina Comportamento do Consumidor.

A disciplina Comportamento do Consumidor visa muni-los com um conhecimento [...]. As atividades que vocês deverão desempenhar estão expostas no "mapa" apresentado na sequência. [...] É interessante notar que muitas organizações não conhecem profundamente o seu consumidor, muito menos o que o seu consumidor pensa realmente sobre elas. Veja uma reportagem exemplar sobre o assunto em texto da revista Exame (Disponivel em: http://exame.abril.com.br/negocios/gestao/noticias/ sua-empresa-pior-voce-imagina-551171? page $=1 \&$ slug name $=$ sua-empresa-pior-voce-imagina-551171).

PARE E PENSE

Por que as empresas agem assim, ou seja, não estão efetivamente atentas ao consumidor? Seria por ignorância ou escolha consciente?

Desta forma, para se ter informações adequadas sobre o consumidor, necessário se faz compreender o comportamento de consumo desse ator do mundo organizacional.

(Professor cursista 6 - FPAEAD-T8, CEaD/UFU, 2013) 
E a tutora formadora destaca:

Importante dizer que você manteve um diálogo na construção do material quando coloca os itens "Saiba mais" e "Pare e pense". Segundo meu ponto de vista, esses itens correspondem a momentos de reflexão a serem desenvolvidos pelos alunos (Tutora formadora 1, FPAEAD-T8, $\mathrm{CEaD} / \mathrm{UFU}, 2013$ ).

Ao acompanhar este movimento entre a tutora formadora e seus colegas de turma, e usar os recursos do Moodle, o professor que até então as desconhecia e não tinha experiência em $\mathrm{EaD}$, em outra atividade, já ensaiou a produção de uma escrita que proporciona maior diálogo professor-aluno:

Olá, pessoal! Iniciaremos hoje os estudos relativos à introdução ao Direito. Teremos muito trabalho pela frente. Mas também muitas surpresas e descobertas. Começamos agora nossa navegação. [...]

Nesta primeira unidade vamos traçar as linhas gerais sobre o que é o Direito, analisando a estrutura de suas normas e destacando a diferença entre Direito Público e Direito Privado. Logo a seguir, faremos um estudo sobre as Fontes do Direito. [...] Leia a Unidade 1 do material impresso. Tenha sempre em mente que a leitura de um texto acadêmico requer disciplina quanto à pesquisa das palavras que você desconhece. Recorra ao dicionário, se necessário. [...]

(Professor cursista 5 - FPAEAD-T8, CEaD/UFU, 2013)

Também explorou a ferramenta Fórum do Moodle para promover a interação entre os alunos da turma:

Acesse a página http://www.stf.jus.br/portal/principal/principal.asp. Clique no icone jurisprudência e, a seguir, no campo "pesquisa livre", digite alguma palavra que você entenda que diz respeito à Administração Pública, por exemplo: servidor público, aposentadoria, capacitação, etc. Em seguida, escolha umas das palavras das quais leu alguma decisão. Elabore um pequeno texto a respeito (máximo 20 linhas), registrando também suas impressões. Poste, no fórum, seus registros sobre o julgamento, relacionando-o ao contexto brasileiro atual. Acompanhe e comente a postagem de seus colegas.

(Professor cursista 5 - FPAEAD-T8, CEaD/UFU, 2013) 
Tal mudança vai ao encontro do que Zuin comenta:

\begin{abstract}
Não se pode ser ingênuo a ponto de se acreditar que a presença física do professor garanta por si só o ensino de boa qualidade, haja vista o fato de prevalecer, em muitas ocasiões presenciais, o denominado pacto da mediocridade, no qual o professor finge que ensina e os alunos fingem que aprendem. [...] Na verdade, a presentificação do professor se faz, paradoxalmente, por meio de sua "virtualização", ou seja, pela possibilidade de se espicaçar o desenvolvimento de um número cada vez maior de representações que estimulem os alunos a questionar os conteúdos transmitidos, os quais, ao invés de serem absorvidos, podem ser elaborados criticamente (ZUIN, 2006, p. 948).
\end{abstract}

Enfim, a dinâmica do curso de formação de professores para atuar na $\mathrm{EaD}$, ao gerar a interação entre professores cursistas com diferentes níveis de experiência na educação a distância com os tutores formadores e o AVA, contribuiu para que os professores que atuarão na $\mathrm{EaD}$ iniciassem ou revisassem suas metodologias de ensino e aprendizagem nesta modalidade de educação, que tem suas especificidades para aproximar o que parece distante.

\title{
REFERÊNCIAS
}

ARRUDA, E. P.; FREITAS, M. T. M. Educação a Distância na UFU: alguns percursos históricos e a implantação do curso de Pedagogia/UAB. In: ARRUDA, Eucídio Pimenta (Org.). Educação a Distância no Brasil: a Pedagogia em foco. Uberlândia: EDUFU, 2012.

BRASIL. Edital n ${ }^{\circ} 1$, de 16 de dezembro de 2005. Diário Oficial [da] República Federativa do Brasil, Brasília, 20 dez. 2005, p. 39, seção 3.

BAKHTIN, M. Marxismo e Filosofia da Linguagem. São Paulo: Hucitec, 1986.

BAKHTIN, M. Estética da Criação Verbal. Tradução a partir do francês de Maria Ermantina Galvão G. Pereira. 3. ed. São Paulo: Martins Fontes, 2000.

BEHRENS, M. A. Projetos de aprendizagem colaborativa num paradigma emergente. In: MORAN, J. M.; MASETTO, M. T.; BEHRENS, M. A. Novas tecnologias e mediação pedagógica. 21. ed. rev. e atual. Campinas: Papirus, 2013. 
BRUNO, A. R. Aprendizagem do adulto: contribuições para a construção de uma didática online. In: FREITAS, Maria Teresa de Assunção (Org.). Cibercultura e formação de professores. 1. ed. Belo Horizonte: Autêntica, 2009, v. 1, p. 99-115.

CORTELAZZO, I. B. de C. Tutoria e autoria: novas funções provocando novos desafios na educação a distância. EccoS - Revista Científica, São Paulo, v. 10, n. 2, p. 307-325, jul./dez. 2008.

FREITAS, M. T. A. A formação de professores diante dos desafios da cibercultura. In: FREITAS, M. T. A. (Org.). Cibercultura e formação de professores. Belo Horizonte: Autêntica, 2009.

FREITAS, M. T. M. A Formação do Professor na Era da Mudança de Paradigma Educacional. In: FIDALGO, Fernando S. R.; CORRADI, W.; FAVACHO, A. P.; ARRUDA, E. P. (Org.). Educação a distância: meios, atores e processos. 1. ed. Belo Horizonte: CAED, 2013.

IMBERNÓN, F. Formação permanente do professorado: novas tendências. São Paulo: Cortez, 2009.

MASETTO, M. T. Mediação pedagógica e tecnologias de informação e comunicação. In: MORAN, J. M.; MASETTO, M. T.; BEHRENS, M. A. Novas tecnologias e mediação pedagógica. 21. ed. rev. e atual. Campinas: Papirus, 2013.

OLIVEIRA, C. M. B.; SOBRINHO, J, A. C. M. Os saberes docentes na Educação a Distância: reflexões teóricas sobre a prática pedagógica do professor autor. Trabalho apresentado no VI ENCONTRO DE PESQUISA EM EDUCAÇÃO PPGED/UFPI. $O$ pensamento pedagógico na contemporaneidade. Teresina: EDUFPI, 2010. Disponível em: <http://www.ufpi.br/subsiteFiles/ppged/arquivos/files/VI.encontro.2010/GT.17/ GT_17_09_2010.pdf>. Acesso em: 04 abr. 2012.

PRETI, O. Educação a distância: fundamentos e políticas. Cuiabá: UFMT, 2009.

VYGOTSKY, L. Pensamento e Linguagem. São Paulo: Martins Fontes, 1991.

ZUIN, A. A. S. Educação a distância ou educação distante? O programa Universidade Aberta do Brasil, o tutor e o professor virtual. Educação \& Sociedade, Campinas, v. 27, n. 96 - Especial, p. 935-954, out. 2006.

Texto recebido em 22 de novembro de 2014. Texto aprovado em 10 de dezembro de 2014. 